\title{
Syntactic devices expressing focus in English and Kurdish: A comparative study
}

\author{
Arazoo Rashid Othaman ${ }^{1}$
}

\begin{abstract}
Received: May 25, 2016 Reviewed: June 20, 2016 Accepted: July 12, 2016

Languages can have different devices to express different types of information such as focus, in which certain elements in a sentence are given a special prominence to represent the most important new information in that sentence. Hence, the present paper deals with syntactic aspects of focus in English and Kurdish. The study comprises three chapters. Chapter one is devoted to the analysis and discussion of syntactic aspects of focus in English. It covers different devices that are used to express focus in English including: passsivization, cleft constructions, topicalization, postponement, extraposition and existential construction. Chapter two presents an analaysis of Kurdish Syntactic focus. It explores Syntactic devices in Kurdish to express focus which include: Interrogtaive and Exclamative sentences, complements, passivization and topicalization. Chapter three conducts a comparative analysis of syntactic focus in English and Kurdish and highlights some points of similarity and difference between the two languages. Finally, the most important findings of the paper are presented.
\end{abstract}

Keywords; Kurdish language, Interrogtaive, exclamative sentences, complements, passivization and topicalization

$$
\text { بوخته }
$$

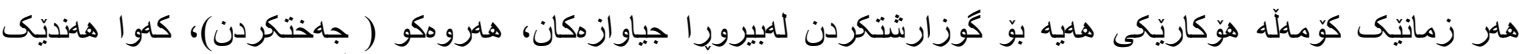

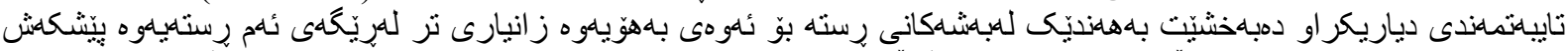

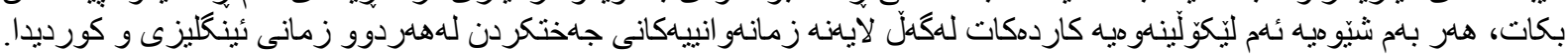

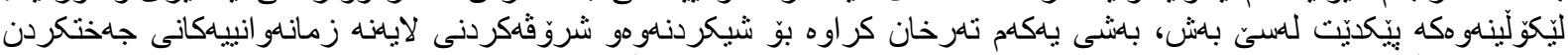

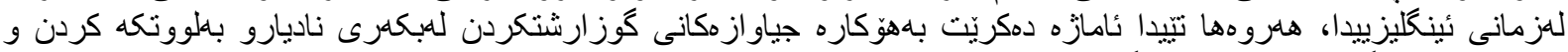

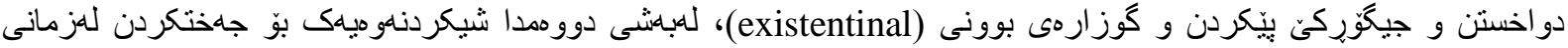

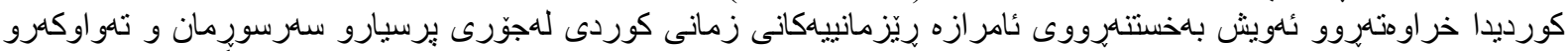

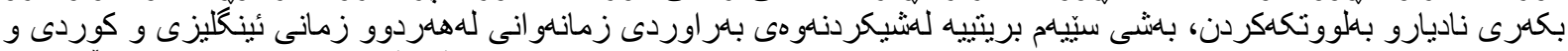

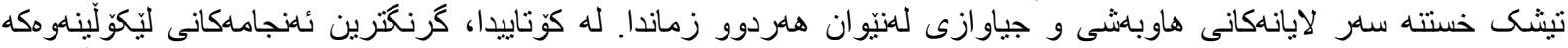

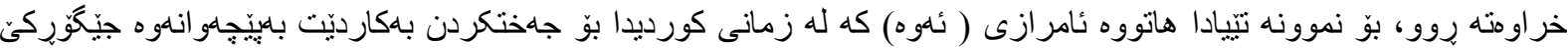

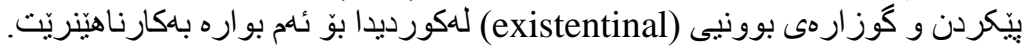

Recommended citation:

Othaman, A. R. (2016). Syntactic devices expressing focus in English and Kurdish: A comparative study. International Journal of Kurdish Studies 2 (2), 1 - 14.

\footnotetext{
${ }^{1}$ Corresponding Author: English language Depatment, Koya University, Kurdistan Region of Iraq.

Email: Arazoo.Rashid@koyauniversity.org
} 


\section{INTRODUCTION}

All languages have focus but the devices by which they are expressed vary across languages. English and Kurdish have different devices for expressing focus especially syntactic devices of focus. So it is natural for syntactic devices of focus to become an interesting topic for study. To the researcher's best knowledge, Kurdish syntactic focus has not received much attention and no book has conducted the details of the topic. Thus, this makes it interesting to investigate.

The aim of this study is to identify the syntactic devices by which focus is expressed. To this end, a comparative analysis is conducted to bring out the points of similarity and difference related to syntactic focus in both languages. This study can be of value to teachers as it is expected to provide a source of reference for field workers and theoretical linguists who are interested in focus.

\section{Operational Definitions}

Syntactic devices: a set of syntactic means that are used to refer to an abstract design constructed to enable an analysis to be made. (Crystal, 1988: 134)

Passivization: is a term used to refer to a construction in which its underlying object appers as its surface subject and its underlying subject being either absent or expressed as an unimportant agent.

Cleft constructions: Trask (1993: 46) defines it as a marked structure in which a focused constituent is extracted from its logical position and often set off with some additional material.

Topicalization: The phenomenon in which some element of a sentence is signaled out as the topic by the use of a marked construction.(Trask, 1993: 280)

Extraposition: is a postponement which involves the replacement of the postponed element by a substitute form. (Quirk et al, 1985: 1391).

\section{METHODOLOGY}

The present study is an analytical study. The researcher contrives the data from different sources on grammar in both languages about syntactic focus. The researcher relied on ( Quirk, R. Greenbuam, S. Leech, G and Svartivik H. (1985).A Comprehensive Grammar of the English Language. London: Longman) to analyse focus in English and (Muhammad, Shiler R. (2010). Focus devices In Kurdish. Journal of the Kurdish Academy, No. 15, 15 38.) to analyse focus in Kurdish.

\section{LITERATURE REVIEW}

There are some studies on focus in English but no studies have been conducted under this title which is a contrastive analysis of syntactic focus in English and Kurdish. 


\section{Syntactic devices of Focus in English}

Focus relates to new information i.e it tells the hearer where the new information is given. This section is concerned with studying the devices by which the hearer understands which piece of information is given prominence, These devices in English include the following:

\subsection{Passivization}

A transitive verb can be focused on by the use of a passive construction provided that the agent can be ignored as either given or dispensable, as in :

1. The instructors completely mentioned all the points.

2. All the points were completely mentioned.

In the second sentence the noun phrase (the instructors), which is present in the first sentence, is ignored; so the verb element (mentioned) is focused on through passivization.

The indirect object can also be focused on through passavization in sentences with ditransitive verbs, as in:

3. They gave him a book.

4. He was given a book.

Huddleston (1984: 17) states that passaivization may have the extra advantage of either allowing ' end focus' or deleting the agent and although end focus belongs to phonology, it clearly has important implications in syntax where the ordering of the constituents of the massage is largely determined. It can influence the choice between active and passive constructions, Compare:

5. Ann washed the dishes.

6. The dishes were washed by Ann.

Concerning end focus, these two sentences presuppose different contexts; for example the first one answers the question: "What did Ann wash? " while the second answers the question: " Who washed the dishes ?".

According to Huddleston, the thematic meaning of omitting the passive agent is that in the passive version we are free to give information which would have to be given in the active. Thus, an agentless passive can be interpreted in a variety of ways, such as:

7. The car was made in 1990.

8. The students read the questions carefully, then all of the questions were answered.

The first example expresses how old the car was, the agent is not known, but even if it was known it would not have been relevant to the issue how old it was, while in the second example the agent is recoverable from the first (the student).

Noun phases that express old information may precede those expressing new information in this case the passive is likely to be preferred (Jwad, 2007:61).

9. I have read a new story. 
10. A new story has been read by me.

Here (a new story) introduces new information into the discourse.

\subsection{Cleft constructions}

The term cleft refers to three types of cleft constructions, they are:

It - clefts , wh- clefts and reverse pseudo - clefts.

11. It was a doll that you hid. (It - clefts)

12. What you hid was a doll. (Pseudo - Clefts)

13. A doll was what you hid. (Reverse clefts)

Quirk et al (1985: 1384) state that the cleft sentence indicates divided focus, and which of the two focused items is new, depends on the context;

14. You should respect his personality.

- No, it is feelings I shall respect.

New Given

15. You should criticize his callousness.

- No, it is his callousness I shall ignore.

New Given

According to Quirk et al the content of the relative clause is normally Given although sometimes the information that is contained in a relative clause may be new but it may not be something important as in the following examples:

16. A.You should ignore his dishonesty.

B. No. it is his callousness I shall ignore.

Furthermore, Broughtan (1990: 151) indicates that it- cleft sentences can be used to express the speaker's attitude, As in:

17. It was quite clear that she could not make head or tail of my announcement.

Moreover, the it- cleft construction can be used to focus on the identity of the highlighted element:

18. It was the head that you met yesterday.

Here, the identity of the highlighted element which is ( the head) is focused on by the speaker. Quirk et al (1985: 1388) state that wh- cleft sentence is less restricted than the it- cleft in a way that it permits the end focus to fall on the predication when the substitute of verb do is used, as in:

19. What he's done is (to) spoil the whole thing.

In this example the focal point is the $d o$ verb. 
Wh- cleft can be used to put more emphasis on the verb, in this case a more complicated structure with what do is used (Swan, 1995: 115).

20. What he does is explaining the whole scene.

Furthermore, there are certain wh- clefts such as what happened was what I mean ...., and the thing is ...., are used to focus on the all sentence (Downing, Locke, 2006: 252).

21. What happened was (that) the story frightened us.

\subsection{Topicalization}

Topicalization takes place when a constituent is moved to the front of a sentence, so that it functions as topic. Such as :

22. The answer I'll give you in a minute (Crystal, 2003: 468)

It can be noted that the emphasis achieved by fronting may be of contrastive kind, also fronting can be used as a device to link the clause to the preceding (and sometimes following) one:

22. This morning he was too ill to go to school but now he's well enough to go and play football.

However, Swan (1995: 217) indicates that adverb particles are often fronted when giving instructions to small children, as in:

23. Here you come.

On the other hand, fronting of adverbials can be used to focus on the important information in the right place (Estwood, $2000: 58$ ).

24. Carefully she listened to the teacher.

Fronting is made when the speaker wants to focus on information which is new or important to the hearer.

\subsection{Postponement}

It is noted that the difference between it- cleft and pseudo cleft is that, in it- cleft the main focus is put near the front of the sentence, while the pseudo cleft is used to postpone the focus to end position.

25. The manufacturers tested the device.

26. The people who tested the device were manufacturers.

(Quirk et al, 1985: 1389)

Downing and Locke (2006: 262) state that postponement can be made in two ways which are: postponement by discontinuous units and postponement with ditransitive verbs. 
In the former an element is postponed to the right rather than to the left, such as postponing quantifier in nominal and adjectival groups. In the latter end - focus is placed either on the recipient or on the other participant.

27. We've given the children bicycles.

We've given bicycles to the children

\subsection{Extraposition}

It refers to the process of moving an element from its normal position to the end or near the end of the sentences (Crystal, 2003: 174). Jwad (2007: 71) distinguished three types of extraposed clauses which are: Extraposed clausal subject in which a subject realized by finite or non- finite clause is moved to the end of the sentence and the subject position is filled by "it", which is called anticipatory it.

28. It Is clear that she is smart.

Extraposed - ing clause is another type of extraposed the clauses in which the normal ing clauses occur in canonical subject positions, as in:

29. Staying in shapes is easy with all the running around I have to do.

I have to do.

The other type is Extraposed clausal object which is distinguished by extraposing the direct object to the end of the sentence and filling its position with anticipatory "it".

30. I realized it is obligatory to organize the game schedual.

One themantic effect of extraposition related to the choice between the unmarked and extraposed constructions is that a context where the content of an embedded finite clause or infinitival is given may forgery the unmarked construction.

31. That it might be a forgery was suggested several years ago by my uncle.

32. It was suggested several years ago by my uncle that it might be a forgery.

In this case example (32) might be preferred over example (33).

\subsection{Existential construction}

A term refers to a type of structure commencing with the unstressed word "there", followed by a form of verb "be", and the notion of existence thereby being expressed, e.g:

33. There is plenty to do.

As it is noted that, organizing sentences in terms of theme and focus presumes that a sentence begins with reference to Given information and proceeds to provide New 
information. However, the recipient expected to interpret a theme as entirely new (Quirk et al, 1985 : 1402).

Furthermore, the unstressed There has no semantic meaning so it is not the participant clause (s), although it has both syntactic function as grammatical subject and a textual function as presentative element, since it replaces the true subject and pushes it to the right or to a position that carries end focus, since it is clarified that moving an element as in there construction introduces new information. As in:

34. There was a big tournament.

35. There was a course of learning computer.

36. There was a peeled paint of the wall.

\section{Syntactic devices of focus in Kurdish}

In Kurdish, there are three devices to construct focus, they are : phonological, morphological, and syntactic focus, Since the concern of the present study is focus through syntactic devices so we will focus on the syntactic focus.

Thematization in Kurdish syntax could be achieved, among other means, through focus. Thematic sentences can be made through different types of sentences when they show focus. These can be outlined as follows.

\subsection{Interrogative sentence:}

The interactive sentences in Kurdish can be constructed through question words such Kê ( who), kay ( when), çi ( what), çon ( how), çand (how, much, how many). They are retained in their position without any syntactical movement. They are focused on through stress while pronouncing (Qadir, 2008, 148).

The speaker can focus on an item he wants such as:

37. Kê hat bo maltan?

Who come - past to home your.

Who came to your home?

38. Kay daçi bo bazaar?

When go - present to market.

When do you go to the market.

39. Çi daheni bo man?

What bring - pre.For us.

What do you bring us?

40. Çon daçi bo aw şwen- a.

How go - pre. To that place - izaf.

How do you go to that place? 
In the above sentences the focus is on the question words, so when these questions are answered they are answered depending on the question words. In this case the focus will be on the information which is newly given.

\subsection{Exclamative sentences}

In exclamative sentences of Kurdish, items are focused through topic stress not through syntactic stress i.e. by proposing the focused item, such as:

41. Ari hamw nanakay xwar!

Ari all breed - the eat - past.

Ari ate all the bread.

Here (hamw nanaka) is focused when the speaker expresses his surprise for eating the bread by Ari (Qadir, 2008: 150).

Exclamative sentences can be made through some words and they are focused to express surprise, as in:

42. Ay ka balay barza!

Oh, hieght tall

Oh, how tall he is.

43. Ax bo aw rož- a.

Alas for that day. Def.

Alas for that day.

44. Dad la dast zordari.

Oh, prep. injustice

I am sick of injustice.

45. Pakw law roža naxoşa.

Oh, prep. day bad

What a bad day today

(Muhammed, 2010:35)

\subsection{Complement}

The complement of a complex sentence may focus on the subject of the sentence, as in:

46. Hawraz ka kuri mamma ziraka.

Hawraz who son uncle clever.

Hawraz who is my cousin is clever.

In this sentence the complement focused on rather than the subject is the speaker's cousin not anyone else. 


\subsection{Passivization :}

In a passive sentence the subject of the sentence is omitted, the objective occupies the subject position which is a grammatical subject and its clearly focused on (Muhammed, 2010: 34).

47. Xanw - aka ruxen - ra

House def. ruine - passive.

The house was ruined.

If we look at the structure of the sentence, there is one grammatical subject which is at the beginning of the sentence and when it is pronounced it is stressed which is syntactic stress. In Kurdish passive sentence, a transitive verb can be focused on, such as:

48. Hamu xal-ak - an amaža- y an pekra

All point def. pl. mention Acc ( accusative) pl. do - past.

All the points were mentioned.

Furthmore, the object can be focused on through passivization, as in:

49. A wan kteb aka yan da ba aw.

They book def. pl. give to him

They gave him the book.

Aw kteb akay pe dra

He book def. accusative marker give passive.

He was given the book.

\subsection{Topicalization}

Topicalization can be constructed through two steps: the first stepis that topicalization can be constructed without moving the topic to the front, such as:

50. Peşmarga azad y kird.

Peşmarga liberate Acc/ $3^{\text {rd }}$ sing.

Peşmarga liberated it.

The second step is to construct topicalization by moving the topic to the front.

51. Kurdistan Peşmarga azad y kird.

Kurdistan Peşmarga liberte Acc/ $3^{\text {rd }}$ sing.

Kurdistan, Peşmarga liberated it.

(Qadir, 2008: 73)

Moreover, Qadir (2008: 91) states that the direct object will be moved to the front of the sentence in past and present sentences: 
52. Mn xanw aka m dirust kird.

I house def. pron. build past

Xanw aka mn dirust $m$ kird.

House def. I build pron past/ do

Mn xanw aka dirust daka $\mathrm{m}$.

I house def. build present.

Xanw aka mn dirusty daka $m$

House def. I build present

An adverb of time as well as an adverb of place can be moved to the front of the sentence in order to be focused on, as in:

53. Êma hafta y rabirdu çu yn bo bazaar.

We week last go - past clitic/ pron. to market

We last week went to the market.

Hafta y rabirdu ema çu yn bo bazaar

Week last we go clitic/ pron. to market.

Last week we went to the market.

54. Awan lawe bun.

They there were.

They were there.

Lawe bun awan

There were they

Furthermore, adverbs of manner and quantity can be focused on through topicalization when thay are moved to the front.

55. Balindakan pol pol koçn dakan.

Bird def. in swarm migrate do - present

Pol pol koçn dakan balind ka an.

There are some prefixes such as (pé, té, lé) verb components, when they are used in syntax they will be changed from morpho- syntactical prefixes to syntactic prefixes.

56. Aw la Sirwan y da

He prep Sirwan Acc/ $3^{\text {rd }}$ sing. Hit

La Sirwan da aw

Prep. Sirwan Acc $/ 3^{\text {rd }}$ sing. Hit he

He hit Sirwan.

(Qadir, 2008: 103- 105) 


\section{A contrastive analaysis}

\subsection{Passivization}

In Kurdish passive sentences, as well as in English, the transitive verb can be focused on, as in:

1. All the topics were neglected.

2. Hamu babt - ak an piştgwé xiran.

All topic def. pl. neglect - passive. Past - Agr

The indirect object in both languages can be focused on through passivization, See section (1. 1$)$ in chapter one, and section (2.4) in chapter two.

\subsection{Cleft constructions}

In English, the three types of cleft constructions can be used to express

focus, such as:

3. It was a car that you sat on.

4. What you sat on was a car.

5. A car was what you sat on.

While in Kurdish the word that can be used to express focus as the cleft construction in English is the Demonstrative Awa, as in:

6. Awa otombel bu ka to lasary daniştit.

That car was that you can sit. Past

It was a car that you sat on.

7. Away ka to lasari daniştit otombel bu.

That that you on sit car was

That you sat on was car.

On the other hand, English wh- cleft sentences permit the end focus to fall on the verb ' do', whereas in Kurdish this only occurs when the verb ' kirdin' is involved, as in:

8. What he did was rewrite the letter.

9. Away (ka) to aw kird - y nusenaway Namaka bu.

That clause marker he did Acc/ $3^{\text {rd }}$ sing rewrite letter v. past

\subsection{Topicalization:}

In English, as well as Kurdish, topicalization is constructed by moving the topic to the front, as in:

10. The cake I well bake later.

11. Kek - aka mn daeka -m la dwayeda. 
Cake daf. I bake pro. Later

The adverbs of time and place in both languages can be fronted to be focused on. See section (1.3) in chapter one and (2.5) in chapter two.

Furthemore, adverbs of manner and quantity can be moved to the front in order to be focused on in both languages, as in:

12. Step by step they were developing.

13. Hangaw ba hangaw peshdakdawtn.

Step by Step develop. Past. Continuous

14. Cleverly he answered.

15. Zerakana walame dayawa.

Cleverly answer verb. Past.

In English, this construction (as in 71) is not canonical; it is marked while in Kurdish it appears to be unmarked since no Kurdish speaker can be found to produce the sentence with the adverb at the end.

\subsection{Postponement:}

Unlike the it - cleft sentence in postponement, the focused item is

postponed to the end of the sentence. This phenomenon can be seen in both language, as in:

16. The engineers designed the plan.

The people who designed the plan were engineers.

17. Andâzyâr akan-n plan aka yan darişt.

Engineer def. pl. plan def. pron (they) designed.

Aw xalk an y ka plan aka yan darişt Andâzyâr bon.

The people who paln def. pron. designed enginereer, V. past.

\subsection{Extraposition and existentinal}

Concerning these two devices which can be regarded as two syntactic

devices to express focus in English, as it is clarified in sections (1.5) and (1.6) in chapter one, in Kurdish these two devices cannot be found since there is not a word like anticipatory ' $i t$ ' in extraposition or unstressed ' there' in existential sentences to be used to construct these types of sentences. However, the demonstrative (aw) can be placed at the beginning of some sentences as in:

18. Awa y ka to kriwta kona ya.

That which you buy. Past old pron. (it)

\subsection{Interrogative and Exclamative sentences}

In Kurdish these two types of sentences can be used to express focus, see sections (2.1), (2.2) in chapter two, but in English they cannot be found to be syntactic devices for expressing focus, as in: 
19. Kay wana ka daxwen y ?

When lesson def. study pron, (you)

When do you study the lesson?

The new information which is given by answering the question will be focused on.

\section{CONCLUSION}

The conclusions drawn from this research can be summarized as follows:

1. The demonstrative (awa) in Kurdish can be used to express focus to refer to the cleft construction in English.

2. Concerning extraposition and existential construction, are two English syntactic devices to express focus while they cannot be found in Kurdish because this language does not allow a word like anticipatory (it) or unstressed (there).

3. In Kurdish, interrogative and exclamative sentences are regarded as syntactic devices to express focus while in English they do not serve this function.

\section{REFERENCES}

Broughton, G. (1990). The Penguin English Grammar A-Z for Advanced Students, London: Penguins books.

Crystal, D. (2003). A dictionary of Linguistics and Phonetics. Oxford: Basil Blackwell.

Downing, A and Philip Lock. (2006). A University Course in English Grammar. London and New York.Routledge.

Estwood, J. (2000). Oxford Guide to English Grammar. Oxford: Oxford University Press.

Huddleston, Rodney. (1984). Introduction to the Grammar of English. Cambridge: Cambridge university press.

Jwad, Hoshang F. (2007). Thematic Meaning In English. Unpublished PhD Dissertation. Koya university.

Muhammad, Shiler R. (2010). Focus devices In Kurdish. Journal of the Kurdish Academy, No. 15, 15 - 38.

Qadir, Karwan O. (2008). Topicalization of sentences in Kurdish Language. Sulaimani: Kurdology Center.

Quirk, R. Greenbuam, S. Leech, G and Svartivik H. (1985).A Comprehensive Grammar of the English Language. London: Longman.

Swan, M. C, (1995).Practical English Usage. Oxford: Oxford University Press. 
Trask, R. L. (1993). A dictionary of Grammatical terms in Linguistics. London and NewYork: Routledge. 